\title{
Construction of SPOC-based Learning Model and Its Application in Linguistics Teaching
}

\author{
https://doi.org/10.3991/ijet.v13i02.7929 \\ Hua Lu \\ Anhui Polytechnic University, Wuhu, China \\ luhua27@163.com
}

\begin{abstract}
Abtract-The design of a reasonable learning model must take the new internet age into consideration. The purpose of this paper is to construct a SPOC-based learning model and demonstrate its effectiveness in the teaching of the linguistics course. Following a contrastive study between MOOCs and SPOCs, a SPOC-based learning model is proposed which consists of four components, 1) the preliminary component composed of anterior analysis and course construction, 2) the restrictive admission component for student number control, 3) the learning procedure component which is subdivided into pre-class session, class session and post-class session, and 4) the evaluation component which includes both online assessment and classroom assessment. Employing a combined qualitative and quantitative method, this paper shows that this model has advantages over previous ones and the application of this model in teaching linguistics to college students shows clearly its effectiveness in increasing participation and learning time, and in improving learning attitude.
\end{abstract}

Keywords-MOOC, SPOC, Learning model, linguistic teaching

\section{Introduction}

The 21 st century is what people usually call the "internet+"age, which means that every person can have access to the world through internet connection anytime anywhere. The new feature of internet surroundings is reinforced by the rapid spreading of mobile laptops, smart phones and communicative phone apps, like Twitter and Wechat. Nowadays, it is possible that the new generations can never live their lives without mobile electronic devices, which may pose a serious challenge to traditional modes of classroom teaching and learning. Teachers and students can either stick to the old-fashioned way of teaching, controlling the use of information technology in class, or find ways to utilize the new age feature and facilitate teaching and learning. It can be easily judged that the second alternative is a wiser choice.

In 1982, the first distance learning program was initiated in the University of Chicago [1], and the online programs grow exponentially thereafter. The first known MOOC (massive open online course) was offered by MIT to provide web access of course materials to students [2]. Currently, there are abundant MOOC platforms in many esteemed universities, which make use of clouding computing systems to offer 
learning opportunities to people all over the world. The term SPOC (small private online course) is coined by Fox [3], a professor at University of California at Berkeley, and the first SPOC was offered at Harvard Law School in 2013, where approximately 500 students are selected from a total of more than 4,000 applicants to participate in the SPOC course. The transformation from MOOCs to SPOCs reflects the popularity of online courses and people's thorough reflection of online learning. In the setting of university education, this change seems to be logical and inevitable. Though there are many studies on the advantages and disadvantages of these two course models, a proper and exact learning model utilizing SPOCs has yet to be established, and this is one major concern of this paper.

Linguistics is the scientific study of language which can be divided into subbranches concerning sound, structure and meaning [4]. This discipline is a compulsory course for language majors which usually lasts for one or two semesters. One important feature of linguistics is its systematicity and abstractness, which makes it difficult to learn for initial learners. Another purpose of this paper is to apply the SPOC-based learning model to present a specific learning agenda of linguistics teaching, so that the efficiency of teaching and learning of this course can be improved.

\section{From MOOCs to SPOCs: A Changing Model of Online Platforms}

In this section, the MOOCs and SPOCs are discussed in detail, with a focus on their practices and features. After that, a comparative observation is presented to show the necessity of changing from MOOCs to SPOCs against the background of university education.

\subsection{The emergence of MOOCs}

Since its appearance in 2012, MOOCs are now a common theme in the educational system. Currently, there are about 100 platforms that offer MOOCs, with the cooperation of leading institutions of higher education and top scholars as well as industry experts in different areas of learning. There were originally three major American MOOC providers, i.e. Coursera, edX and Udacity. Now more MOOC platforms are created in other countries, e.g. FutureLearn in the UK, Open2Study in Australia, Iversity in Germany and France Université Numerique in France [5].

MOOCs are online courses which offer educational chances to potential applicants all over the world, usually free of charge. A typical MOOC usually consists of a series of video lectures, assignments, computer-based tests and online discussion forums [6]. Students are accepted usually in a large number without limit. These MOOCs give open access to originally controlled learning materials and chances of education in an asynchronous and interactive manner. The students can even receive a certificate when finishing a course. The essential feature of MOOCs can be generalized as accessibility, which gives the general public a channel to learn any subject they choose, regardless of previous learning experiences. While in the past, these opportunities 
were only available to only a limited number of elite university students. The idea of creating MOOCs opens up the possibility of creating a genuine pathway for life-long learning processes, which is of critical importance in the current fast-paced, highly competitive society.

\subsection{The emergence of SPOCs}

MOOCs are divided into xMOOCs and the cMOOCs [7]. The previous type follows the traditional classroom learning model with video lectures chosen by instructors, while the latter usually resorts to pedagogies based on learner networks and connectivism (a theory of learning in a digital age that emphasizes the role of social and cultural context in how and where learning occurs) to help learners acquire new knowledge. In recent years, there is also a tendency to combine the two types to create derivative types of MOOCs. SPOCs are just one of the course types emerged following the rise of the grand-scale online MOOC wave.

SPOC is pioneered through the edX platform and it can be defined as a curriculum education model which employs MOOC resources to the physical environment of learning on campus. A SPOC is modeled on XMOOC which includes instructor videos, interactive assignments, and discussion groups [8]. Some scholars generalize the feature of SPOCs as the combination of MOOCs plus classroom [9]. When a new SPOC is opened, the applicants need to write admission essays and the instructor can choose a specific number of students, usually under 500, based on essay-writing adequacy of the applicants. This elicitation procedure offers instructors a chance to obtain more insights concerning their students and adjust the supervision methods to satisfy learners' idiosyncratic learning needs. The accepted learners are mentored by oncampus students and receive the same requirements of the course expected of a regular student. They become drop-outs if they cannot keep up with the learning process, which maintains the quality of teaching. Seen from this way, a SPOC resembles the flipped classroom pattern [10] of learning more than a MOOC.

SPOCs change the status of traditional way of classroom teaching in the physical environment. It is a hybrid model integrating online learning and traditional classroom learning offered to a small group of learners. A SPOC can employ the resources of MOOCs through instructor design, and promote learner-teacher interaction and the improvement of academic performance. SPOCs give full play to the merits of MOOCs while remedy some of their disadvantages. As a result, SPOC platforms with a school-learning basis receive more popularity over the recent years.

\subsection{Comparing MOOCs and SPOCs}

MOOCs are usually created and promoted by prestigious top universities which provide free access to learning opportunities to people all across the globe, and they are precious resources for learners with strong learning motivation and less financial support. Accompanying this advantage, there are also some disadvantages.

Firstly, since MOOCs are completely open to the public without a selection procedure for a short period of learning span, all people can participate in MOOCs, which 
brings a huge number of online learners and high rate of dropout. The completion rate is usually less than $15 \%[11]$.

Secondly, the learning method of MOOCs is unitary with an emphasis on selflearning. There is no information sharing, multi-modal curriculum templates, or class management. Furthermore, operation demonstration, case analysis, and group discussion are rarely employed.

Thirdly, the evaluation strategies to access students' learning outcomes are limited, with a focus on self-assessment and peer-assessment [12], while some other more efficient evaluation methods are neglected.

Fourthly, the ideology of teaching is not completely changed in MOOC platforms from traditional teaching. MOOCs are the electronic representation of traditional class structure and teaching content. Investigative learning and individual learning requirements are not met.

Fifthly and finally, the equipment of learning of MOOCs is usually limited to PCs. The confrontation of machines can bring exhaustion and boredom to students, which dampens students' motivation of learning.

On the contrary, the SPOC model can compensate the shortcomings of the MOOC model. Firstly, a SPOC is controlled in the sense that a fixed number of students are chosen with potential abilities of finishing the courses. The control of candidates brings a high rate of class attendance and course completion, which can reach $90 \%$ [13]. A SPOC usually lasts for a whole semester, the time span for regularly-enrolled students. Secondly, since SPOCs combine MOOC resources with classroom instruction, all the procedures lacking in MOOCs can be remedied through teacher-student interaction. Thirdly, with teachers' participation and classroom involvement, other efficient and diversified assessment strategies can be added. Fourthly, with a combination of MOOCs and traditional classroom teaching, SPOCs create a blended learning environment, which is truly a drastic change in terms of teaching pedagogy and teaching ideology. Finally, the learning equipment in SPOCs can be increased to include the Blackboard Learning Management System (a virtual learning environment and course management system developed by Blackboard Inc.), physical learning materials, white-board, smart phones, etc., which brings diversity to the learning process. The major points of the two models are summarized in Table 1.

Due to the advantages of SPOCs over MOOCs, this paper argues that the SPOC model should be employed as the basis for learning model construction. Against the background of higher education, the SPOC-based model can provide an important channel for teachers and students to maximize learning resources to make progress in study. The following problem would be the exact learning model that can be constructed with the employment of SPOCs, and this will be the topic of the following section. 
Table 1. Differences between MOOCs and SPOCs

\begin{tabular}{|c|c|c|c|}
\hline No. & Perspective & MOOCs & SPOCs \\
\hline 1 & openness & completely open & controlled \\
\hline 2 & student selection & all permissive & competitive selection \\
\hline 3 & candidate number & large-scale & small-scale \\
\hline 4 & time span & short & regular \\
\hline 5 & attendance rate & low & high \\
\hline 6 & finishing rate & low & self-made or adopted \\
\hline 7 & teaching materials & self-made & online + classroom \\
\hline 8 & learning method & online & diversified \\
\hline 9 & evaluation strategies & monotonous & relatively high \\
\hline 10 & education cost & low & \\
\hline
\end{tabular}

\section{Construction of SPOC-based Learning Model}

In this section, the principles of building a learning construction are presented first. After that, taking these principles as guidance, this paper proposes the SPOC-based learning model.

\subsection{Principles of learning model construction}

There are three principles that must be taken into consideration when a learning model is constructed, i.e. the principle of systematicity, the principle of interaction, and the principle of initiative.

A teaching system is the intentional arrangement of resources and process. Any ingredient, which is intended to explore people's potential of learning, should be included into the system [14]. In the same way, in the design of a teaching model, any activity or component which may bring positive effect upon the learning outcome should be considered in the model, for example, learners, the instructors, the teaching aids, technology, resource design and selection, evaluation procedure, feedback mechanism. People should appraise and integrate them into the model if possible. Furthermore, these ingredients should receive systematic and orderly organization. This is why the principle of systematicity is important in the design of a teaching model.

In learning, learners inevitably encounter problems, and the solution to problems usually comes from group work. The communication between co-learners facilitates learners in terms of meaning construction of the knowledge they are aiming for [15]. This is why the principle of interaction is important. In the design of a teaching model, online and offline communication between students are both of critical importance. They can work together to make full use of learning materials and resources, and solve specific problems through the way of teamwork and group cooperation. If the principle of interaction is fully implemented, students will become active agents en- 
gaging in learning, rather than receptive entities, which may bring drastic change to the learning result.

According to constructivist learning theories, learning is not the passive acceptance of stimulus information, but the active construction of knowledge by the learners themselves [16]. The students, when they are in the process of learning, should be encouraged to raise questions, air views, and participate in the process of learning. The result is that the learners should take an active role in the learning process. A learning model should take the inspiration of students' learning initiative as one key issue, so that students can enhance their learning consciousness and improve learning efficiency.

\subsection{SPOC-based learning model}

Based on the previously mentioned principles, this paper proposes a SPOC-based learning model which is organized in a liner and systematic way. This model is represented in figure 1.

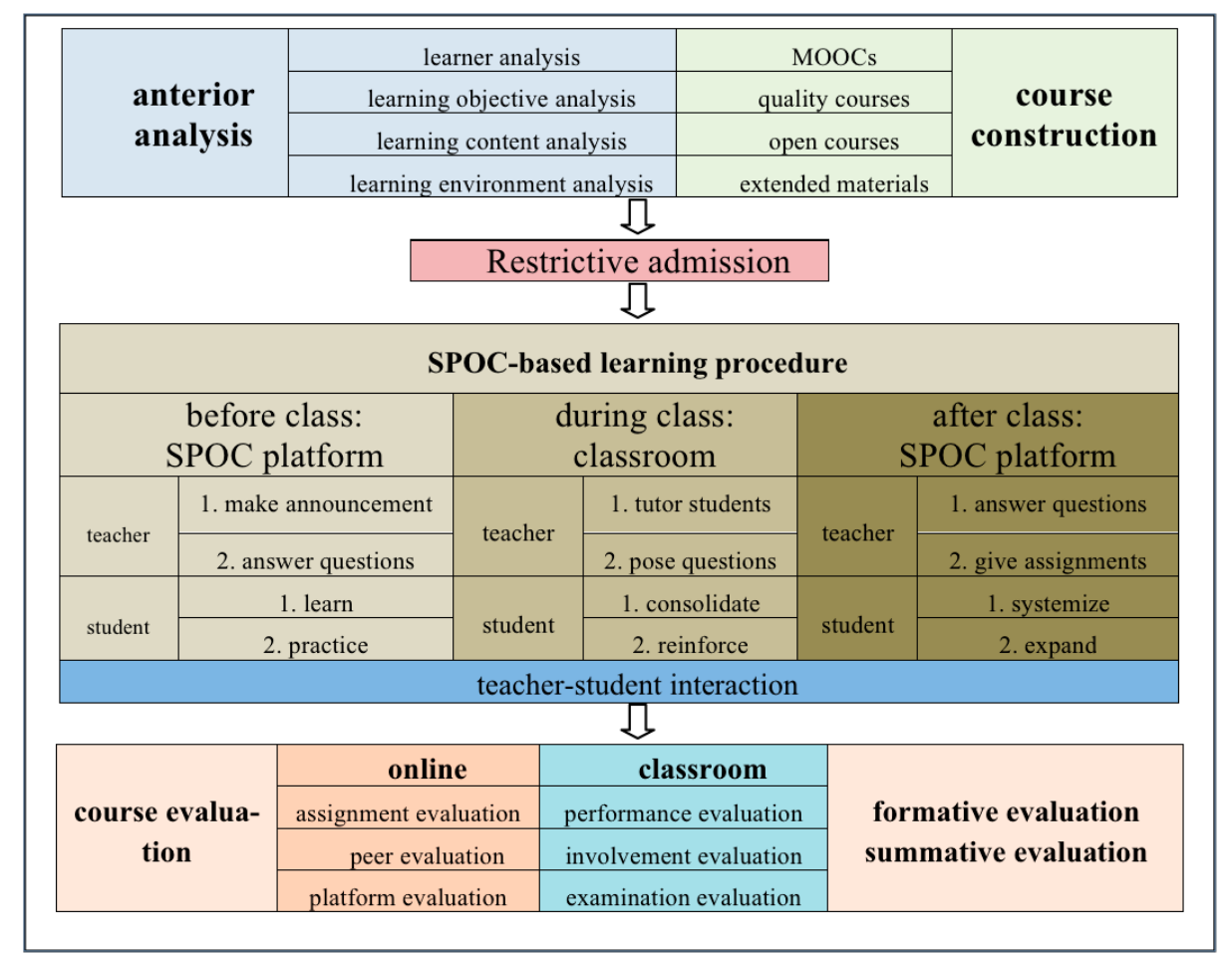

Fig. 1. SPOC-based learning model

The SPOC-based learning model consists of four components, and they are the preliminary component, the restrictive admission component, the learning procedure component, and the evaluation component. The purpose of restrictive admission is to 
control the number of applicants to avoid the negative effect of large-scale and diversified learner pool, which is an often discussed demerit of MOOCs. The remaining three parts are analyzed in detail in the following part.

The preliminary component has two subparts, i.e. anterior analysis and course construction. Anterior analysis mainly focuses on the assessment of the background of learning which includes the assessment of learners, learning objective, learning content, and settings for learning. Course construction is of critical importance in the SPOC-based learning model, and the courses may be MOOCs or high-quality courses created by different teaching groups that are open to one specific university or to the general public. Furthermore, some extended materials can also be included in this model.

The learning procedure is divided into three subparts, i.e. the pre-class part, the class part, and the post-class part. The pre-class part sets the stage for learning where teachers give students specific directions while students make use of the online SPOCs to achieve basic learning goals. They also need to do a specific amount of exercise to check the effect of learning. In classroom learning, teachers do not have to focus on every detail of the course. They should rather focus on critical points or raise questions to ensure the quality of learning. Students can consolidate what they have learned and reinforce their understanding towards the objective and content of learning. In the post-class part, students have to do more exercises and read more advanced materials to establish a systematic view of what they have learned; some top students can even start investigative learning or start their projects to achieve even more results. Throughout the three subparts, teachers and students can always interact with each other so that feedback can be transmitted and both parties can adjust themselves to achieve maximum learning effect.

The evaluation component is carried out through formative evaluation methods and summative evaluation methods. The online performance and classroom performance are both taken into consideration to offer students holistic and objective assessment.

\subsection{Advantages of SPOC-based learning model}

The SPOC-based learning model has some advantages over previous learning models. The aim of this section is to present and discuss in detail five advantages of this model.

Firstly, this model preserves students' learning attentiveness. The SPOC-based learning model has modular mini-lectures and highly pertinent exercises. The students, before the classroom session, self-study the mini-lectures through a series of videos followed by specific and targeted exercises to guarantee understanding. The short span of video playing and the shift between watching videos and doing exercises help maintain high attentiveness of the learners to achieve optimal study effect.

Secondly, this model satisfies individualistic learning needs. Students can replay the videos online, freely arrange their time, place and pace of learning, and pose insightful personal questions towards the course. This freedom realizes individualism in learning to accommodate the needs of a verified circle of learners. 
Thirdly, this model promotes the flipped classroom pattern of teaching and learning. The mini-lectures through videos are given to the students to learn before class. In the class, students and teachers are mainly involved in the activities of analyzing key points, doing exercises, researching on projects, and taking part in group discussion, etc. This flipped pattern avoids the traditional pattern of on-length teaching in the class, and brings promising integration of online learning, offline learning, selflearning, group learning and investigative learning.

Fourthly, this model frees teachers into doing more significant work. A teacher does not need to give a full lecture all through the class, and he or she can be the initiator of learning tasks, the organizer of group discussion, and the coordinator of class activities. These changed roles bring forth new benefits to both teachers and students.

Finally, this model provides meaningful big data for teaching research. The online interaction and evaluation procedure leaves precious raw materials for teachers and researchers to engage in the study of learning path, teaching modes, error patterns, and interactive channels. Consequently, the results achieved through these studies can provide educators with valuable reference information on issues of problem diagnosis, learning intervention and learning policy determination.

\section{$4 \quad$ SPOC-based Learning Model in Teaching Linguistics}

The author has employed the SPOC-based learning model to teach the course of linguistics to English majors in a Chinese university. Taking the chapter of generative syntax as an example, this section focuses on the specific practice of applying this model to the learning process.

\subsection{The preliminary component}

The students are a group of 90 juniors of 3 classes in the School of Foreign Studies who all have the basic required internet and computer skills. They have received the previous English language professional training for two years, and their English proficiency is approximately medium level to advanced level. They all have great interest and confidence in the SPOC-based learning model. The learning objective of this chapter is to understand the basic theories and different schools of generative syntax, while the learning content is syntactic theorizing and analysis of specific languages, especially English and Chinese.

The online learning platform is provided by the academic office of the university. On that platform there is one module dedicated to the course of linguistics. The platform is composed of four parts, the SPOC section, the test section, the forum, and the learning surveillance system, which provides systematic assurance of the learning effect. The SPOC section consists of the following five components as summarized in table 2 . 
Paper-Construction of SPOC-based Learning Model and Its Application in Linguistics Teaching

Table 2. SPOC section composition for the linguistics course

\begin{tabular}{|c|l|}
\hline No. & \multicolumn{1}{|c|}{ materials } \\
\hline 1 & learning videos produced by the teaching group \\
\hline 2 & courses from the National Quality Course Network \\
\hline 3 & materials from digital libraries, eg. Cnki and Wanfang \\
\hline 4 & PPT files for the course \\
\hline 5 & extended reading materials \\
\hline
\end{tabular}

\subsection{The Learning procedure component}

The chapter of generative syntax takes 2 class hours to finish, which lasts for one week's time. The time allotment is shown in figure 2.

\begin{tabular}{|c|c|c|c|c|c|c|}
\hline Tuesday & Wednesday & Thursday & Friday & Saturday & Sunday & Monday \\
\hline & \multicolumn{2}{|c|}{ Online learning } & $\begin{array}{c}\text { Classroom } \\
\text { learning }\end{array}$ & \multicolumn{3}{|c|}{ Online learning } \\
\hline
\end{tabular}

Fig. 2. Time allotment for the chapter of generative syntax

As can be seen in fig. 2, the class meeting takes place on Friday, and the remaining days are separated into two parts for online learning. The previous part is for beforeclass activities and the latter part after-class activities.

On Tuesday, the students are asked to log onto the online learning platform to check the learning syllabus for the week, and they are required to watch the videos and read the extended materials on the platform. The 30 students in one class are divided into 6 learning groups that work together to do exercises independently and find out the right answers collectively. Furthermore, they have to prepare a list of 6 questions for discussion with the group's joint effort. The students are required to finish all the work in three days before Friday. When they have their questions during the process of learning, they can go to the forum system to start a discussion or ask for help from the teacher who will answer the question online or offline.

During the classroom section on Friday, the teacher lists the major schools and theories of generative syntax and asks representatives from the six groups to report their findings, and they are ready to be questioned by either the teacher or their fellow students. After that, a different group of student representatives report their questions and initiate discussions concerning the topics raised. Through these steps, the students deepen their understanding of the originally abstract syntactic theories and are capable of doing practical language analysis.

After Friday, the students have three more days to finish the exercises provided by the teacher on the platform. This time, the students have to do the work all on their own. After that, the students are required to upload their answers to the platform system to be graded. One academic paper on the topic of "modern syntactic analysis" is provided to the students to read. The top students can chat with the instructor through Wechat or QQ (Chinese instant communicative apps) for personal comments and 
further materials. Through this way, the students systemize what they have learned and are ready to go further into the frontier areas of syntactic study. All the students must finish the work before Tuesday when the mission of the following chapter is announced on the learning platform. All through the three stages, when the students have questions, they can always go to the forum or use Wechat and QQ to consult their fellow students or the teacher, so the interaction between learners and instructor occurs all the time.

\subsection{The Evaluation Component}

The evaluation of the linguistics course is divided into two portions, the online portion and the classroom portion. The scores are given according to the assignments and topics posed on the learning platform. Furthermore, the performance of the students in the classroom is also taken into consideration, focusing on the quality of their reports and involvement in classroom activities. The ratio is $60 \%$ online performance plus $40 \%$ classroom performance. At the end of the semester, the students have to take a test which occupies $30 \%$ of the total score, which means that the semester-long performance online and in the classroom occupies $70 \%$. This method of evaluation covers both formative evaluation and summative evaluation, and is a fair procedure generally accepted by the instructor and the students.

\section{Surveys of Students' Reaction to the Learning Model}

After the learning of the chapter on generative syntax, the author conducted a simple investigation concerning students' reaction to the SPOC-based model. The subjects are the 90 students taking the linguistics course. There are three factors under consideration, i.e. learners' participation rate in the learning process, time spent in learning and learners' attitude to the model.

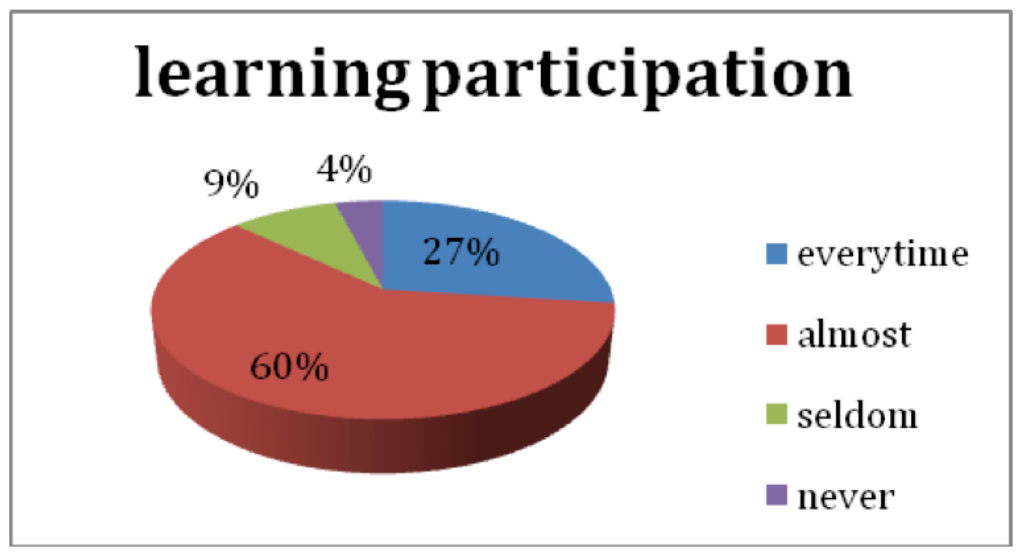

Fig. 3. Survey result of learning participation 
Figure 3 shows that with the online part added to the learning process, a majority of students have participated in the learning process. $27 \%$ of the learners dedicate themselves completely to learning while only $4 \%$ do not participate. These $4 \%$ students have offered their reasons of not participating, and none of the reasons are related to the course design itself. $60 \%$ of the students almost always take part in the process, and $9 \%$ do not contribute enough to learning. For an abstract course like this, this rate is good enough to make a difference.

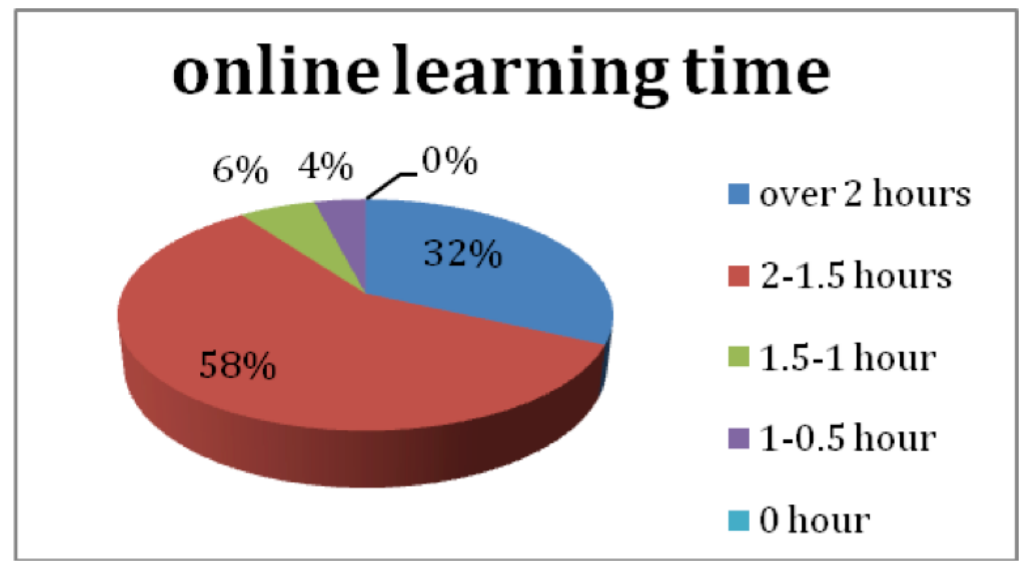

Fig. 4. Survey result of online learning time

In figure 4, it is shown that besides the classroom meeting time, every student logged on the internet to access online materials. The majority of students take 1.5 to 2 hours of online study, $32 \%$ of them study over 2 hours. Students who study less than 1.5 hours occupy only $10 \%$. This shows that students all have interest and willingness in SPOC-based learning. This amount of time spent is one of the important reasons guaranteeing the effect of study.

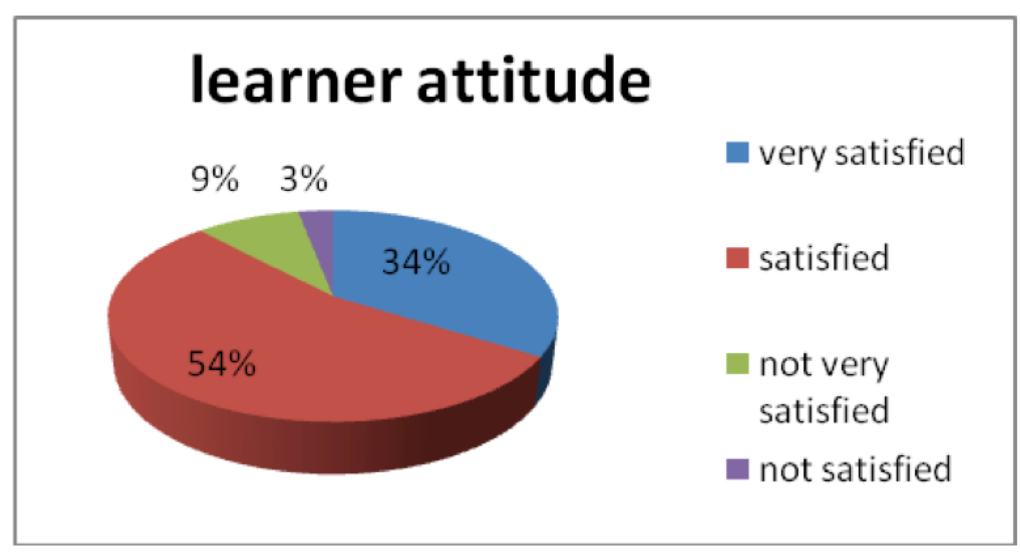

Fig. 5. Survey result of learner attitude 
Figure 5 shows that the students who are satisfied or very satisfied with the model occupy $88 \%$, which means that most of the students have positive feelings on this blended way of learning. The students who are not satisfied provided reasons which mainly cover load of work and difficulty of catching-up, which is not closely related to the model itself. In a different research carried out with the traditional model of teaching, it is shown that students who are very satisfied with this course occupy $0 \%$, students satisfied with the course $13.3 \%$, students not very satisfied $80 \%$, and students not satisfied $6.7 \%$ [17]. When the two sets of data are compared, the advantages of the SPOC-based model can be easily recognized.

These three survey results show that almost all students hold positive response to the SPOC-based learning model and this model can make a significant difference for the students who are taking this challenging course. When the students take part in the learning process actively, and when their interest of learning is motivated, the improved learning effect can be duly expected.

\section{Conclusion}

The traditional learning model overlooks students' individual learning needs and cannot catch up with the fast development of technology and society. On the other hand, the Internet-based courses, when they are properly used, can bring significant change to the ways of teaching and learning, and revolutionize people's conception of education [18]. The SPOC-based learning model as proposed in this paper is just one of the models that can bring positive effect upon learning. This model brings important implications for teachers and students regarding their roles and patterns in the learning process, and reflections upon these changes can help educators rethink and reconstruct more efficient ways of learning. After all, the learning model is an instrument facilitating learning. If learners want to make substantial improvement, they must make an effort in their own learning motivation and course involvement, understandably, with the help of more and more rational and optimal learning models.

\section{$7 \quad$ References}

[1] Harting, K. \& Erthal, M. (2005). History of distance learning. Information Technology, Learning and Performance Journal, 23(1), 35-44.

[2] Philli, O. \& Admiraal, W. (2016). A Taxonomy of massive open online courses. Contemporary Educational Technology, 7(3), 223-240.

[3] Fox, A. (2013). From MOOCs to SPOCs. Communications of the ACM, 56(2), 38-40. https://doi.org/10.1145/2535918

[4] Akmajian, A., Demers, R., Farmer, A. \& Harnish, R. (2010). Linguistics: An Introduction to Language and Communication. Cambridge, MA: MIT Press.

[5] Wilson, L. \& Gruzd, A. (2014). MOOCs - International information and educationphenomenon? Bulletin of the American Society for Information Science and Technology,40(5), 35-40. https://doi.org/10.1002/bult.2014.1720400510 
Paper-Construction of SPOC-based Learning Model and Its Application in Linguistics Teaching

[6] Hoy, M. (2014). MOOCs 101: An introduction to massive open online courses. MedicalReference Services Quarterly, 33(1), 85-91. https://doi.org/10.1080/02763869. $\underline{2014.866490}$

[7] Chauhan, A. (2014). Massive open online courses (MOOCs): Emerging trends in assessment and accreditation. Digital Education Review, 25, 7-17.

[8] Hew, K. \& Cheung, W. (2014). Students' and instructors' use of massive open online courses (MOOCs): Motivations and challenges. Educational Research Review, 12, 45-58. https://doi.org/10.1016/j.edurev.2014.05.001

[9] Admiraal W, Huisman B. \& Pilli, O. (2015). Assessment in massive open online courses. The ElectronicJournal of e-Learning, 13(4): 207-216.

[10] Herreid, C. \& Schiller, N. (2013). Case studies and the flipped classroom. Journal of College Science Teaching, 42(5), 62-66.

[11] Stark, C. \& Pope, J. (2014). Massive open online courses: How registered dieticians useMOOCs for nutrition education. Journal of the Academy of Nutrition and Dietetics, 114(8), 1147-1155. https://doi.org/10.1016/j.jand.2014.04.001

[12] Haber, J. (2014). MOOCs. Cambridge, MA: MIT Press.

[13] Bell, F. (2010). Connectivism: Its place in theory-informed research and innovation intechnology-enabled learning. The International Review of Research in Open and DistanceLearning, 12(3), 98-118. https://doi.org/10.19173/irrodl.v12i3.902

[14] Gagne, R., Wager, W., Golas, K. \& Keller, J. (2005). Principles of Instructional Design. Belmont, CA: Wadsworth.

[15] Jonassen, D., Howland, J., Moore, J., \& Marra, R. (2003). Learning to Solve Problems with Technology. Englewood Cliffs, NJ: Prentice Hall.

[16] Shunk, D. (2015). Learning Theories: An Educational Perspective. London: Pearson.

[17] Chen, X. (2007). Research on the methods of teaching linguistics to undergraduate students. China University Teaching, 12, 39-42.

[18] Martin, F. (2012). Will massive open online courses change how we teach? Communications of the ACM, 55(8), 26-28. https://doi.org/10.1145/2240236.2240246

\section{Author}

Lu Hua is lecturer in the School of Foreign Studies, Anhui Polytechnic University, Wuhu, 241000, China. Her research interests include applied linguistics, English teaching pedagogy, and educational technology. (Email: luhua27@163.com)

Article submitted 02 November 2017. Resubmitted 14 December 2017. Final acceptance 04 February 2018. Final version published as submitted by the author. 